\title{
Characterization of species diversity and forest health using AVIRIS-NG hyperspectral remote sensing data
}

\author{
C. S. Jha ${ }^{1, *}$ Rakesh $^{1}$, J. Singhal ${ }^{1}$, C. S. Reddy ${ }^{1}$, G. Rajashekar ${ }^{1}$, S. Maity $^{2}$, \\ C. Patnaik ${ }^{2}$, Anup Das ${ }^{2}$, Arundhati Misra ${ }^{2}$, C. P. Singh ${ }^{2}$, Jakesh Mohapatra ${ }^{2}$, \\ N. S. R. Krishnayya ${ }^{3}$, Sandhya Kiran ${ }^{3}$, Phil Townsend ${ }^{4}$ and \\ Margarita Huesca Martinez \\ ${ }^{1}$ National Remote Sensing Centre, Indian Space Research Organisation, Hyderabad 500 037, India \\ ${ }^{2}$ Space Applications Centre, Indian Space Research Organisation, Ahmedabad 380 015, India \\ ${ }^{3}$ MS University of Baroda, Vadodara 390 002, India \\ ${ }^{4}$ University of Wisconsin, Madison 53706, USA \\ ${ }^{5}$ University of California, Davis 95616, USA
}

Species diversity and vegetation health are two critical components to be monitored for sustainable forest management and conservation of biodiversity. The present study characterizes species dominance and $\alpha$-diversity of a forest for the selected region in Mudumalai Wildlife Sanctuary (MWS), Western Ghats, which represents one of the most economically important forest types in India - the tropical dry deciduous forest. NASA's Next-Generation Airborne Visible and Infrared Imaging Spectrometer (AVIRIS-NG) data at spectral resolution of $5 \mathrm{~nm}$ and spatial resolution of $5 \mathrm{~m}$ were used to analyse the forest matrix. Biodiversity $(\alpha$-diversity) map thus generated from airborne platform over $14.5 \mathrm{sq} . \mathrm{km}$ area mostly represents the forest tree species diversity. Dominant tree species in the study area were also mapped using AVIRIS data for $21.7 \mathrm{sq}$. km. Canopy emergent dominant species, viz. Anogeissus latifolia, Tectona grandis, Terminalia alata, Grewia tiliifolia, Syzygium cumini and Shorea roxburghii were classified using spectral angle mapper technique and image-based spectra in the MWS study site. The study shows that nearly $40 \%$ area is dominated by $A$. latifolia and $27.5 \%$ by $T$. grandis in the study site. This study concludes that AVIRIS data can be used in the delineation of species and $\alpha$-diversity mapping at community level; however, the accuracy achieved for species classification is moderate $(60 \%)$ due to intermixing of species in the study area. For the Shimoga study site in Karnataka, the field spectra were collected using a spectroradiometer and used for the classification for the three dominant tree species using absorption peak decomposition technique. Fieldcollected pure spectra were analysed and species-wise absorption peaks (Gaussian) with central wavelength, peak amplitude and dispersion were used as the endmembers for classification. AVIRIS-NG data over Shoolpaneshwar Wildlife Sanctuary (SWS) study site used for fuel load estimation with narrow band indices calculated from AVIRIS-NG datasets. AVIRIS-NG data for MWS and Shimoga study site were collected during 2 and 5 January 2016, while for SWS site data were collected on 8 February 2016.
Keywords: Airborne sensors, forest health, hyperspectral imaging, species diversity.

\section{Introduction}

SUSTAINABLE management of forest ecosystems and biodiversity conservation necessitates explicit knowledge of the spatial distribution of species. Remote sensing data from the earth observation systems have played an increasingly important role in mapping forest types and broad-scale patterns of forest change ${ }^{1-3}$, but have poor capability of discriminating species in case of diverse

\footnotetext{
*For correspondence. (e-mail: chandra.s.jha@gmail.com)
}

tropical forests. The description of spatial heterogeneity of tropical forest ecosystems requires very high spatial resolution and high spectral resolution imaging so as to discriminate target species. Understanding and analysis of seasonality in terms of tree phenology is a major parameter in distinguishing species, as it changes the chemical (pigments)-structural properties (phyllotaxy) that influence their spectra ${ }^{4}$. A guiding hypothesis driving spectral species discrimination is that, species differ in chemistry and structure enough to create consistently unique and detectable spectral signatures among them at one or multiple times through a year. Canopy architecture of the tree is described by leaf area density, leaf and branch zenith angles, leaf shape, internal anatomy, and leaf and branch surface roughness. Any difference in 
canopy architecture causes different tree species to have different reflectance spectra.

Spectral variation among tree species is primarily controlled by their tissue chemistry, structure and changes in these factors through time ${ }^{5,6}$. The reflectance of light from a vegetated ground surface is determined by several factors, such as leaf and canopy geometry, morphology, plant physiology, plant chemistry, soil type and climatic conditions $^{7}$. Vegetation reflectance is primarily influenced by the optical properties of plant materials (including proteins, lignin, cellulose, sugar, starch), which are composed largely of hydrogen, carbon, oxygen and nitrogen. Chemical properties of tissues such as leaves, flowers, fruits and woody branches produce distinct absorption features in reflectance spectra. The absorption bands observed in vegetation arise from vibrations of $\mathrm{C}-\mathrm{O}$, $\mathrm{O}-\mathrm{H}, \mathrm{C}-\mathrm{H}$ and $\mathrm{N}-\mathrm{H}$ bonds as well as overtones and combinations of these vibrations. In green leaves, photosynthetic (chlorophyll) and accessory pigments (particularly chlorophyll $a$ and $b$, carotenoids and xanthophylls) dominate absorption features in the visible spectrum (VIS: $400-700 \mathrm{~nm})^{8}$ and water produces absorption features in the near-infrared (NIR: $700-1327 \mathrm{~nm}$ ) at 970 and $1200 \mathrm{~nm}$ respectively ${ }^{9,10}$. In the shortwave infrared (SWIR: 1467-2500 nm), relatively low reflectance and strong absorption by water in green leaves often mask other chemical absorption features such as lignin, cellulose and nitrogen, that can otherwise appear in dry tissues $^{9,11}$.

Healthy green vegetation is characterized by low reflectance of blue and red light (absorbed by chlorophyll for photosynthesis), and higher reflectance at green wavelength regions. Absorption in the red region at $680 \mathrm{~nm}$ and a rapid increase in reflectance from $680 \mathrm{~nm}$ to $780 \mathrm{~nm}$ are known as the 'red edge'12,13, which often forms an extreme slope. The spectral difference between green and dying (or chloritic) leaves occurs primarily in the region of 400-800 $\mathrm{nm}$ (ref. 14), as absorption of incident light by chlorophyll decreases. As chlorophyll content begins to decrease with stress, leaf reflectance increases initially at the chlorophyll absorption band of 610 , and then at 690 and $710 \mathrm{~nm}$. Dry vegetation lacks chlorophyll and intense water absorption.

A number of studies have indicated the advantages of narrow-band data to obtain the most sensitive information on species-level discrimination using lab spectra ${ }^{15,16}$, airborne spectra ${ }^{17,18}$ and spaceborne spectra ${ }^{19-21}$ by applying different classification algorithms. Hyperspectral remote sensing has the potential to resolve the spatial and spectral discrimination problems and to provide a biophysically based approach for mapping biodiversity ${ }^{17}$. Most of these hyperspectral studies were carried out for boreal and temperate forest ecosystems. These areas are relatively more homogeneous compared to tropical forests. The tropical forests having high plant species diversity, leading to high spectral diversity as well.
Studies have shown that the Hyperion imaging spectrometer on-board the Earth Observing One (EO-1) satellite has provided significantly enhanced data over conventional multispectral remote sensing systems ${ }^{22,23}$. This has led to improved mapping of forest vegetation characteristics such as biochemical-biophysical quanti$\operatorname{ties}^{24}$ and species discrimination ${ }^{25}$. Development of baseline spectral data and tools for the characterization and detection of tree species as a function of hyperspectral characteristics was identified as the priority area of remote sensing research in tropical forests before a decade $\mathrm{ago}^{26}$. However, successful studies based on Hyperion are limited because of intermixing of individual tree crowns at $30 \mathrm{~m}$ spatial resolution. Improved spatial resolution of hyperspectral imagery generally overcomes the intermixing issues of individual species in complex forest ecosystems. Presently, the increased spatial resolution in the hyperspectral domain is mostly from aerial or drone platforms. Airborne visible infrared spectrometer (AVIRIS) data have been used for urban tree mapping, invasive species mapping and understanding the canopy chemistry and nitrogen cycle ${ }^{27-29}$. Xiao et al. $^{27}$ used AVIRIS data for urban forest tree species mapping. Asner et al. ${ }^{30}$ used AVIRIS data for invasive species mapping in Hawaiian forests. Goodenough et al. $^{31}$ studied AVIRIS hyperspectral imagery for forest parameter estimation and found AVIRIS data suitable to estimate some forest stand parameters. Gamon et al. ${ }^{32}$ used AVIRIS hyperspectral imagery to evaluate spatial patterns of vegetation type, productivity and potential physiological activity. In principle, images recorded by airborne or satellite-based sensors can be obtained at reasonably frequent intervals, at desired spatial and spectral resolutions. However, an airborne hyperspectral imaging instrument can collect data at 3-4 m spatial resolution with smaller area coverage compared to a spaceborne instrument.

Hyperspectral analysis of the vegetation provides detailed understanding of the phenology, which in turn is influenced by the climatic regimes, and hence the spatial patterns and processes of vegetation also need to be addressed in terms of climatic variability such as rainfall. Rainfall variability has significant impact on vegetation growth. Tree species exposed to environmental variability over longer timescales show distinctive response towards cyclical events such as rainfall. Responses amongst deciduous species include start of season, end of season and variability in the duration of active green leaf phase. Monitoring of tree species phenological changes is not only important to understand the cyclical behaviour of the species to changing climate, but also to ascertain the feedback mechanisms impacted by climate $^{33,34}$. There are few reports available regarding this for tropical deciduous regions of the world, and Wolkovich et al. ${ }^{35}$ highlighted the importance of research with a focus on collecting data about phenology and investment strategy outside temperate mid-latitudes. 
Table 1. Details of the study area

\begin{tabular}{llcl}
\hline Site & Study component & Area (sq. km) & Data collection date \\
\hline Mudumalai Wildlife Sanctuary (MWS) & Species discrimination & 21.7 & 5 January 2016 \\
& $\alpha$-Diversity mapping & 14.5 & \\
Shoolpaneshwar Wildlife Sanctuary (SWS) & Fuel load estimation & 397 & 8 February 2016 \\
Shimoga Forest division & Species discrimination & 1343 & 1 and 2 January 2016 \\
\hline
\end{tabular}

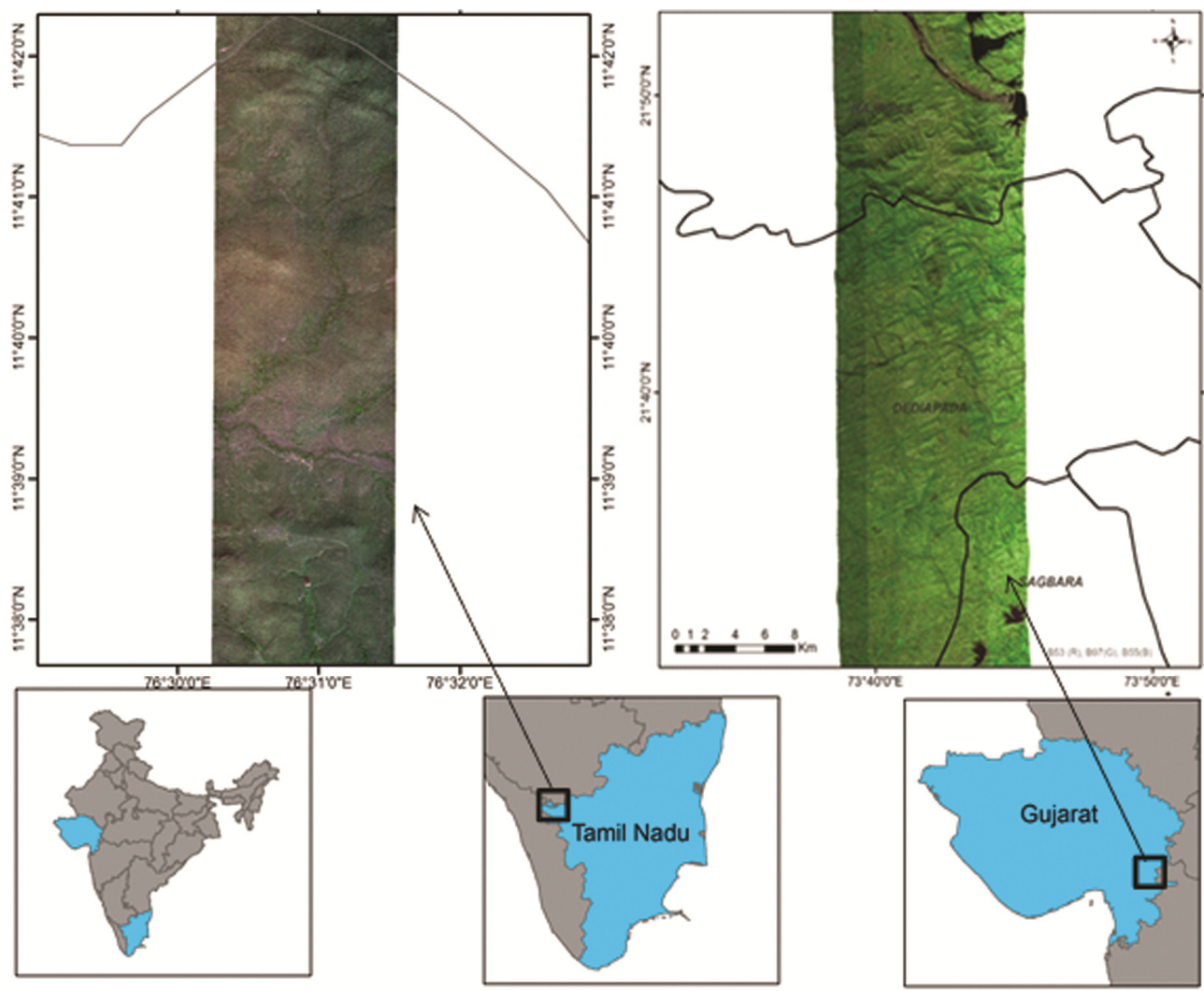

Figure 1. Study area map showing AVIRIS-NG data over Mudumalai Wildlife Sanctuary (MWS; Tamil Nadu) and Shoolpaneshwar Wildlife Sanctuary (SWS; Gujarat).

Species were classified directly from hyperspectral reflectance spectra based on leaf spectra, typically involving a data reduction/feature extraction step, including principal component analysis (PCA) and wavelet transforms, stepwise band selection and narrowband indices, that seek to reduce noise and target discriminating spectral features. These reduced sets of predictor variables have been used with supervised classifiers, including spectral angle mapper, maximum likelihood, decision trees, neural networks, log linear, quadratic and $k$-nearest neighbour ${ }^{36-40}$. Hyperspectral remote sensing of tropical forests is still new, with only a few studies in the published literature ${ }^{41}$. Féret and Asner ${ }^{41}$ developed an unsupervised method to estimate the diversity and similarity in species composition. These findings are the first direct and spatially explicit remotely sensed estimates of alpha and beta diversity of tropical forests. In this study we quantify the $\alpha$-diversity of a forest by estimating Shannon-Weiner index $H^{\prime}$ for the selected region. Six canopy-dominant emergent species in the study area were mapped using AVIRIS data. We also analysed the AVIRIS-NG hyperspectral bands based on vegetation fuel load indices.

\section{Study area}

The study was carried out in three sites to demonstrate the uses of AVIRIS-NG datasets for forestry applications. These sites are: (1) Mudumalai Wildlife Sanctuary (MWS), Tamil Nadu; (2) Shoolpaneshwar Wildlife Sanctuary (SWS), Gujarat and (3) Shimoga Forest (Karnataka). Table 1 provides details of the study sites.

MWS is dominated by tropical deciduous forest. It lies on the northern and northwestern side of the Nilgiris, 
Tamil Nadu, Western Ghats between $11^{\circ} 32^{\prime}$ and $11^{\circ} 43^{\prime} \mathrm{N}$ lat. and $76^{\circ} 22^{\prime}$ and $76^{\circ} 45^{\prime} \mathrm{E}$ long. (Figure 1), covering an area of $321 \mathrm{sq} . \mathrm{km}$. The terrain is undulating, with elevation ranging from 440 to $1260 \mathrm{~m}$ amsl. Rainfall varies from $600 \mathrm{~mm}$ in the east to $1800 \mathrm{~mm}$ in the west. Geologically, the rocks are of peninsular gneiss. Due to both topographic and climatic variations, the site is considered as unique in its distribution of species composition and biodiversity. According to Reddy et al. ${ }^{1}$ there are four main forest types in the sanctuary: tropical semievergreen, tropical moist deciduous, tropical dry deciduous and southern tropical thorn forest.

AVIRIS-NG data over SWS were used for fuel load estimation applying the vegetation parameters. The study site is situated between $21^{\circ} 30^{\prime} 51^{\prime \prime}$ and $21^{\circ} 52^{\prime} 55^{\prime \prime} \mathrm{N}$ lat., $73^{\circ} 38^{\prime} 55^{\prime \prime}$ and $73^{\circ} 44^{\prime} 52^{\prime \prime} \mathrm{E}$ long. covering approximately 397 sq. $\mathrm{km}$ area. The sanctuary has two distinct forest types, viz. southern tropical moist deciduous forest and southern tropical dry deciduous forests ${ }^{42}$.

AVIRIS-NG data over Shimoga Forest Division situated between $13^{\circ} 50^{\prime}$ and $14^{\circ} 10^{\prime} \mathrm{N}$ lat., $75^{\circ} 15^{\prime}$ and $75^{\circ} 35^{\prime} \mathrm{E}$ long. were used for species mapping employing the absorption peak decomposition technique.

\section{Materials and methods}

In the present study, AVIRIS-NG data have been utilized for species dominance mapping utilizing image-based spectra, species diversity index mapping, forest species mapping with ground spectra collected using ASD spectroradiometer, forest fuel load estimation and understanding leaf phenology with respect to rainfall. Data used and methodology are explained in following sections.

AVIRIS-NG data used in this study have 425 narrow continuous spectral bands in the VNIR and SWIR regions in the range $380-2510 \mathrm{~nm}$ at $5 \mathrm{~nm}$ interval with high SNR (signal-to-noise ratio, $>2000$ at $600 \mathrm{~nm}$ and $>1000$ at $2200 \mathrm{~nm}$ ), with accuracy of $95 \%$ having FOV (field of view) of $34^{\circ}$ and IFOV (instantaneous field of view) of $1 \mathrm{~m} \mathrm{rad}$. ENVI and MATLAB were used for data processing. The AVIRIS-NG data were distributed in an ENVI-compatible format: each image was a binary image 'cube' with a detached ASCII header file.

\section{Data used}

About 21.7 sq. km area in MWS was selected for species mapping using AVIRIS hyperspectral data. A subset of 14.5 sq. km was used for mapping $\alpha$-diversity. The study area represents tropical dry and moist deciduous forest. Hyperspectral AVIRIS-NG (NASA's Next-Generation Airborne Visible and Infrared Imaging Spectrometer) data at spectral resolution of $5 \mathrm{~nm}$ and spatial resolution of $5 \mathrm{~m}$ were used in the present study for species domin- ance and $\alpha$-diversity mapping at MWS. Table 1 gives the date of AVIRIS data acquisition. Anogeissus latifolia, Terminalia alata and Tectona grandis have low leaf area due to deciduous condition as part of vegetative phenological cycle.

AVIRIS data for SWS were also used to study the phenological behaviour of four dominant species at SWS and MWS with respect to annual rainfall. Rainfall datasets for MWS and SWS study sites were obtained from TRMM and PERSIANN. AVIRIS data for SWS were analysed for fuel load estimation using narrowband vegetation indices. AVIRIS data acquired over Shimoga Forest were used for species mapping with field spectra for three species collected using an ASD spectroradiometer during the field survey.

\section{Field data}

Field inventory data collected at 21 sample plots (each $0.1 \mathrm{ha}$ ) were used to identify dominant species in the $\mathrm{Mu}$ dumalai Wildlife Sanctuary. Geographic coordinates of each sample plot were collected using GPS. Sample plots were chosen based on distribution of vegetation communities, according to earlier studies in the region ${ }^{43}$. The data on GBH (girth as breast height), height and species names were recorded at each plot. Reflectance spectra were collected 19 tree species in Shimoga Forest for species mapping in the region. Reflectance measurements were done using an ASD spectroradiometer (350$2500 \mathrm{~nm}$ ) during field survey. The sensor with FOV of $25^{\circ}$, was placed $30-40 \mathrm{~cm}$ above the samples at nadir position. Prior to each measurement, a white reference panel with approximately $100 \%$ reflectance was used as a reference standard. At least 8-10 spectral signatures were taken for each species and average of these spectra was taken as reflectance spectra for that particular species.

\section{Dominant species mapping at MWS study site}

Species information collected during field survey was used to identify dominant species at the MWS study site. AVIRIS-NG images for the given area were used to collect the image spectra for the corresponding species class using geographic location of the plot in the image. Analysis was focused on canopy emergent individuals of tree species of the study site dominated by A. latifolia, $T$. alata, G. tiliifolia, S. cumini, S. roxburghii and T. grandis. Spectral angle mapper classification technique was used for species mapping employing image spectra. Image spectra for six dominant species were used for mapping. Additional data of 15 plots were used for validation of species dominance map. Validation of the classification is limited by geographic location accuracy of handheld GPS; use of differential GPS (DGPS) will further improve the accuracy. 


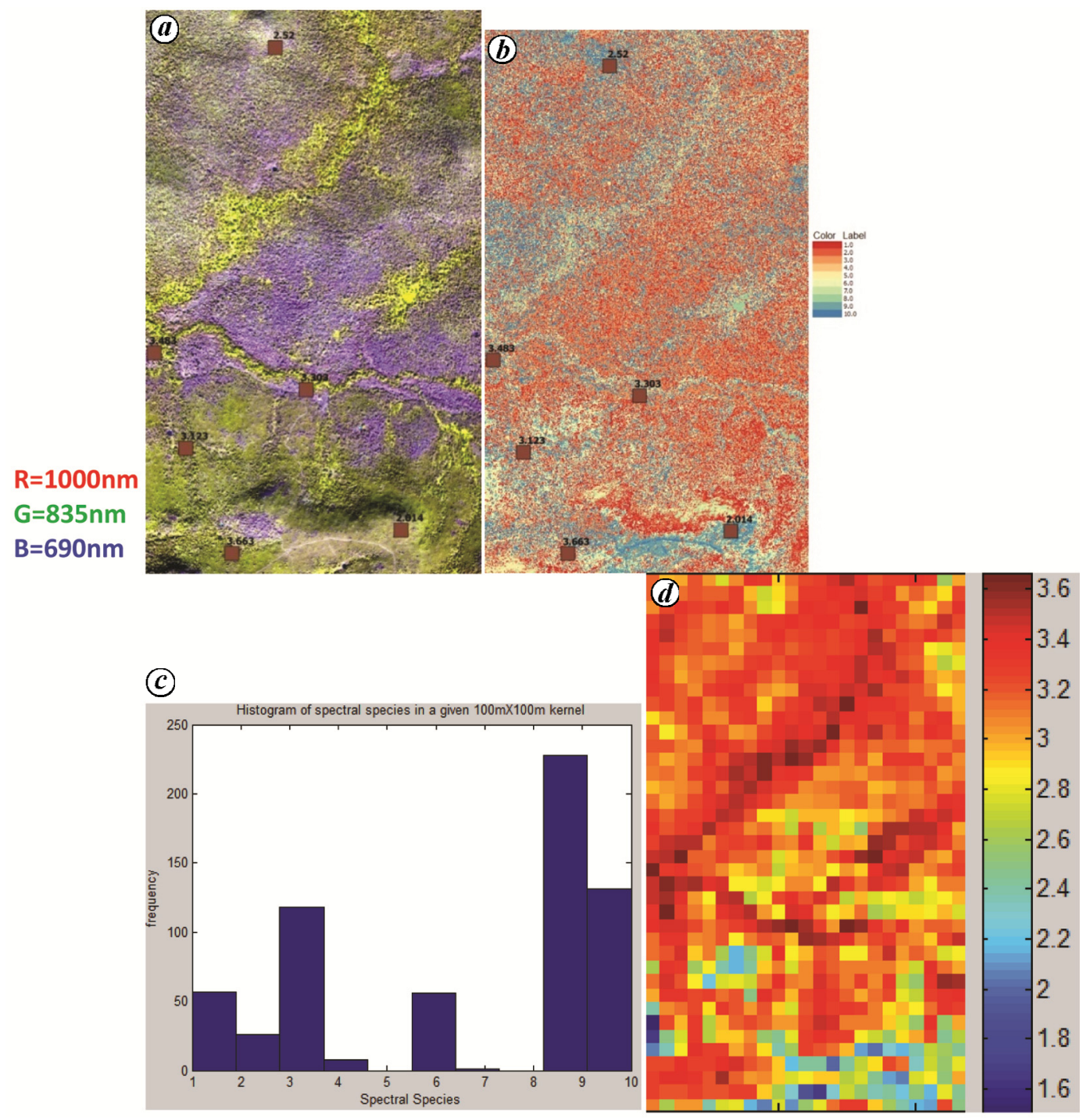

Figure 2. $\boldsymbol{a}$, Hyperspectral data of the region. $\boldsymbol{b}$, Spectral species classified map. $\boldsymbol{c}$, Population distribution of spectral species within a kernel (mapping unit). $\boldsymbol{d}$, Shannon diversity index map.

\section{Alpha-diversity mapping}

The following methodology was applied to the atmospherically (based on modified ATREM algorithm) ${ }^{44}$ corrected georeferenced AVIRIS-NG datasets of the MWS region:

(1) Among 425 bands, the high-noise bands (water vapour absorption bands) were omitted (44 bands) from the dataset by visual interactive observation at the ENVI image analysis software; the remaining 381 bands were used for further analysis.

(2) PCA was applied to the spectral data. The first ten principal components (PCs) explained $99.827 \%$ of the variance in the datasets and hence only these were used to decrease spectral dimensionality.

(3) A subset of pixels was randomly selected from the entire mapped landscape. The spectral space (PCs) containing this subset was partitioned into spectral species using $k$-means clustering ( $k=10$ was assumed based on field data), and the location of the centroid of each spectral space was saved.

(4) The hyperspectral data were gridded in $100 \mathrm{~m} \times$ $100 \mathrm{~m}$ kernels. Within each mapping unit, every image pixel was assigned to a given spectral species based on the minimal Euclidean distance between the pixel and the previously defined centroids.

(5) Shannon-Weiner index was also calculated from field inventory data (six plots of 0.1 ha each). These values were used to calibrate Shannon-Weiner index calculated from AVIRIS-NG data (Figure 2). The linear regression between field measured $H^{\prime}$ and AVIRIS-NG measured $H^{\prime}$ gave an $R^{2}$ of 0.865 (Figure 3).

(6) Ground-calibrated Shannon-Weiner index map was generated using regression equation and AVIRIS-NG calculated $H^{\prime}$ index.

(7) Major limitations in this methodology are as follows: (a) The sensor is only able to see top and dominant 
canopies; so sensor-derived $H^{\prime}$ is a measure of the same, while calibration is done with $H^{\prime}$ derived from plot data which comprise a larger set of trees. (b) Trees which are smaller that the pixel size can get totally redundant. Also, several pixels will have mixed signatures coming from more than one tree, which will be assigned a spectral species with the most dominant signature. So these studies are spatial resolution-specific. (c) The study requires prior ground knowledge, both for calibration purposes and for running $k$-means clustering (number of species noted on the ground is used as an input).

\section{Absorption peak decomposition technique}

Spectra of three dominant tree species (T. grandis, Dalbergia latifolia and Lagerstroemia lanceolata) were collected in the Shimoga study site. Spectra were filtered, smoothened and shoulders of absorption peaks were estimated for hull (continuum). Normalized continuumremoved spectra were generated according to the following equation for further analysis

$$
C=\frac{R_{\mathrm{C}}(\lambda)-R_{\mathrm{T}}(\lambda)}{R_{\mathrm{C}}(\lambda)},
$$

where $R_{\mathrm{C}}(\lambda)$ is reflectance of the continuum; $R_{\mathrm{T}}(\lambda)$ the reflectance from the target and $C$ is the normalized continuum-removed spectrum. Reflectance from vegetation is dominated by absorption features of plant pigments like chlorophyll $a$ and $b$, carotenoids, lignin with nitrogen, cellulose, protein and water. As different tree species have different amounts of pigment present in the vegetation, the peak centre, peak amplitude and peak width will also be different. Thus, each species has a set of absorption peaks, which is unique. Peaks having amplitude less than 0.05 were not considered as a member of the peak set. Smaller amplitude of absorption peak makes it difficult to discriminate the species, hence peaks having smaller amplitude are not considered.

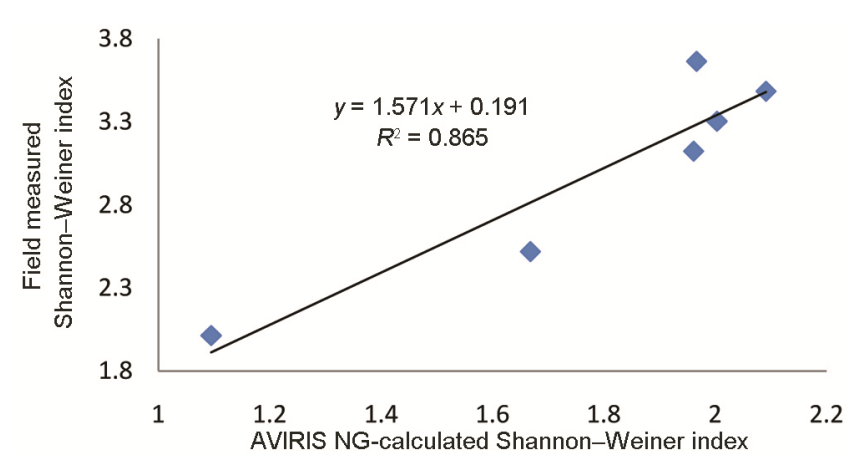

Figure 3. Linear regression between AVIRIS-NG imagery-derived Shannon-Weiner index and field-measured Shannon-Weiner index values. The regression equation is used to generate calibrated ShannonWeiner index map.
As observed in Figure $4 a$, these normalized spectra are very broad and skewed to contain number of hidden children peaks. It is well documented in the field spectroscopy that these types of hidden peaks are in general Gaussian in nature. Normalized broad peaks are decomposed into a number of hidden peaks using parametric nonlinear least square fitting approach. It is observed that each of these broad peaks inherits 2-3 hidden peaks with varying parameters (peak amplitude, centre and standard deviation). In Figure $4 b$, decomposed peaks are shown inside the broad normalized spectrum. These peak parameters pertaining to the species are considered for final 'endmember parameters' selection. Using the same procedure, a set of peak parameters for three species is made and termed as endmember- 1 to endmember- $n$. Unique and non-overlapping set of peak centres and associated parameters like amplitude and dispersion, is finally assigned as 'endmember parameters'.

\section{Fuel load estimation using narrowband vegetation indices}

Following indices were used for fuel load estimation: (1) Modified red edge normalized difference vegetation index (MRENDVI): This index capitalizes on the sensitivity of the vegetation red edge $(705 \mathrm{~nm})$ to small changes in vegetation stress conditions $(750 \mathrm{~nm})$ and to eliminate the effect of surface reflectance (by incorporating $445 \mathrm{~nm})^{45}$.

$$
\operatorname{MRENDVI}=\frac{\rho_{750}-\rho_{705}}{\rho_{750}+\rho_{705}-2 * \rho_{445}} .
$$

(2) Moisture stress index (MSI): This a reflectance measurement that is sensitive to increasing leaf water content.

$$
\mathrm{MSI}=\frac{\rho_{1599}}{\rho_{819}} .
$$

(3) Plant senescence reflectance index (PSRI): This is designed to maximize the sensitivity of the index to the ratio of bulk carotenoids (for example, alpha-carotene and eta-carotene) to chlorophyll.

$$
\text { PSRI }=\frac{\rho_{680}-\rho_{500}}{\rho_{750}} .
$$

By comparing the results of different Vegetation Indices (VIs) in a particular category, and correlating these to field conditions measured on site, we could assess that the above indices are likely to perform better and also well-suited for modelling the variability of fuel load in a given area. These indices were used in mapping relative amounts of vegetation components, which were then 

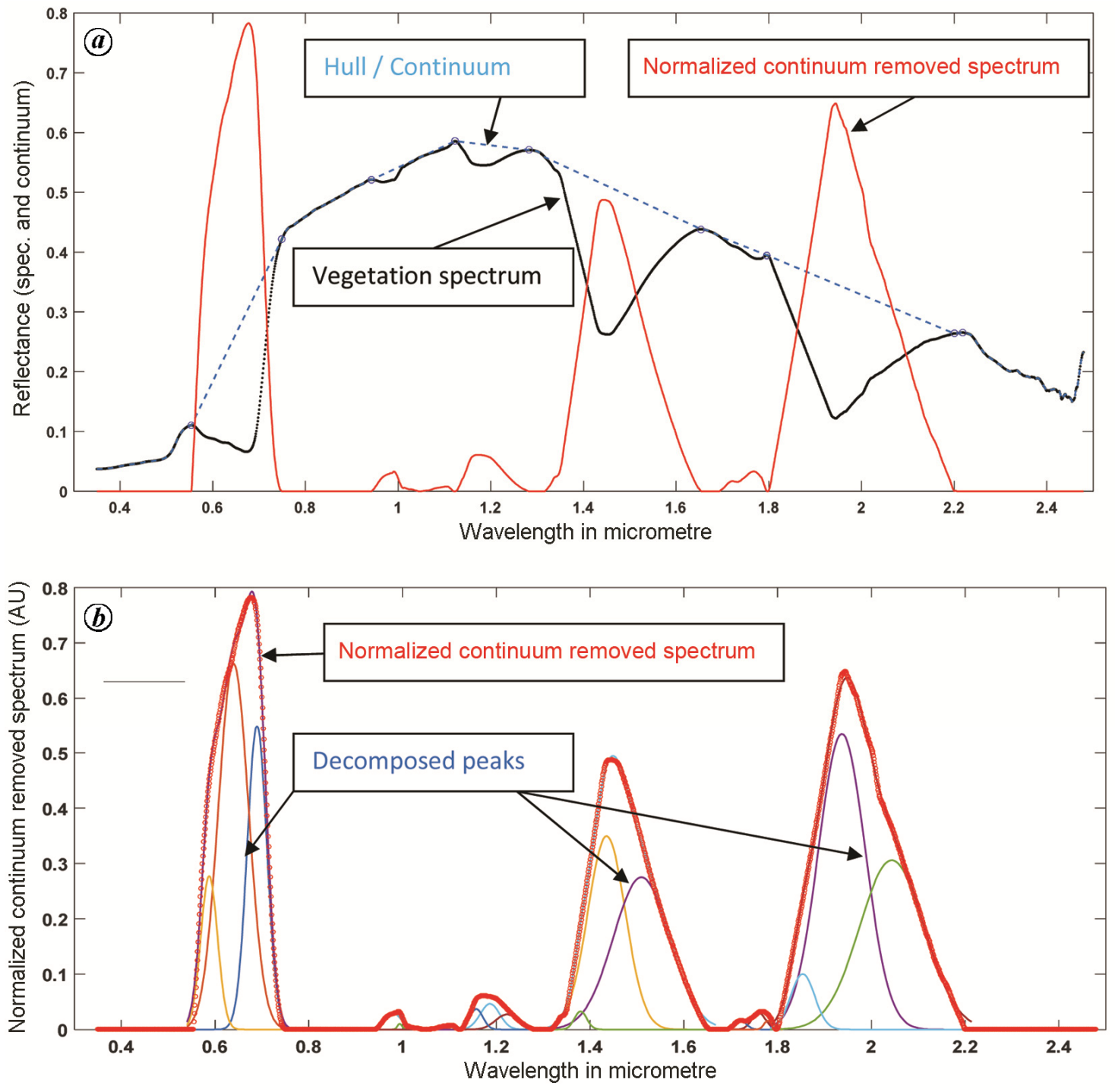

Figure 4. $\boldsymbol{a}$, Vegetation spectrum of a sample target, peak shoulders, continuum and normalized spectrum. $\boldsymbol{b}$, Normalized spectra decomposed to maximum possible Gaussian peaks which are hidden within the broad peak.

Table 2. Species and their importance value index (IVI) calculated based on field survey at the MWS study site

\begin{tabular}{|c|c|c|c|}
\hline Species & IVI & Species & IVI \\
\hline Anogeissus latifolia & 56.76 & Olea dioica & 3.83 \\
\hline Tectona grandis & 47.27 & Albizia amara & 3.26 \\
\hline Terminalia alata & 29.62 & Ougeinia oojeinensis & 3.22 \\
\hline Syzygium cumini & 19.75 & Bambusa arundinacea & 3.18 \\
\hline Grewia tiliifolia & 17.28 & Kydia calycina & 3.07 \\
\hline Shorea roxburghii & 16.05 & Acacia chundra & 2.96 \\
\hline Lagerstroemia microcarpa & 12.34 & Butea monosperma & 2.66 \\
\hline Radermachera xylocarpa & 9.87 & Terminalia arjuna & 2.54 \\
\hline Schleichera oleosa & 8.64 & Chloroxylon swietenia & 2.53 \\
\hline Mangifera indica & 6.79 & Diospyros montana & 2.46 \\
\hline Dalbergia latifolia & 6.81 & Givotia rottleriformis & 2.39 \\
\hline Phyllanthus emblica & 6.24 & Schrebera swietenioides & 2.36 \\
\hline Cassia fistula & 5.78 & Careya arborea & 2.33 \\
\hline Erythroxylum monogynum & 4.68 & Terminalia bellirica & 2.32 \\
\hline Terminalia paniculata & 4.25 & Stereospermum personatum & 2.32 \\
\hline Ziziphus xylopyrus & 4.14 & Buchanania lanzan & 2.30 \\
\hline
\end{tabular}




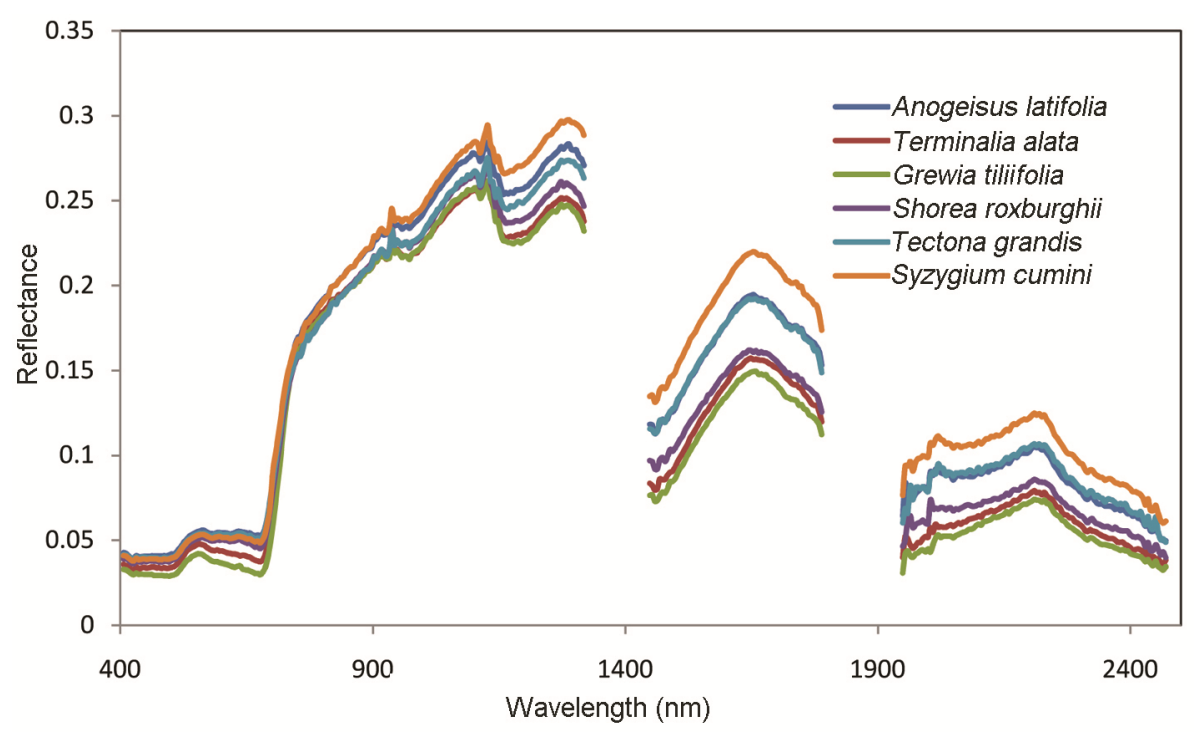

Figure 5. Reflectance curve for six dominant species in the study area.

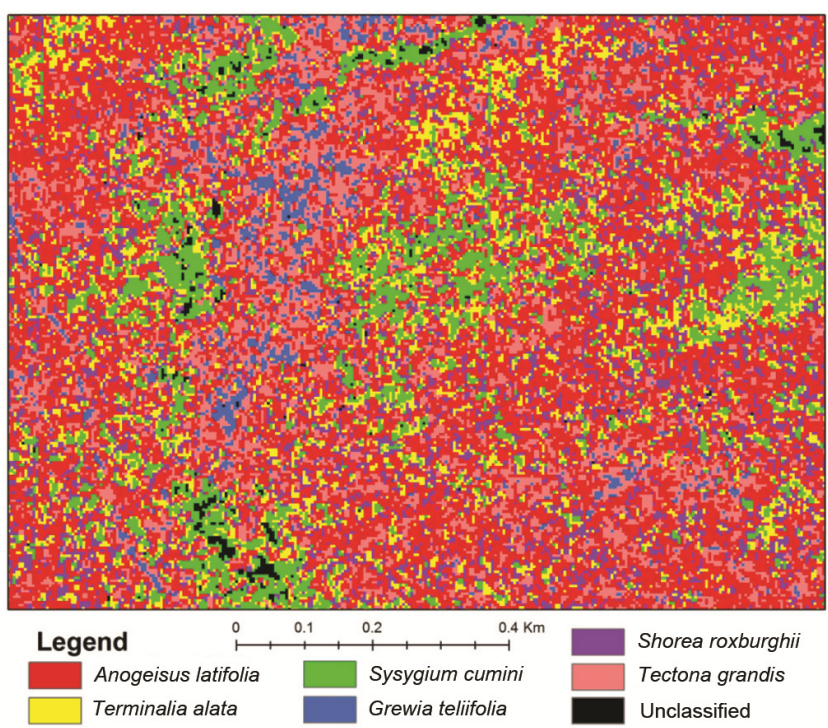

Figure 6. Spatial distribution of canopy dominant species.

Table 3. Area under different species dominance at the MWS site

\begin{tabular}{lcc}
\hline Dominant species & Area (sq. km) & Percentage \\
\hline A. latifolia & 8.6 & 39.8 \\
T. alata & 2.2 & 10.1 \\
G. tiliifolia & 1.2 & 5.6 \\
S. cumini & 1.6 & 7.4 \\
S. roxburghii & 1.9 & 8.8 \\
T. grandis & 6.0 & 27.5 \\
Unclassified & 0.2 & 0.8 \\
\hline
\end{tabular}

integrated through overlay analysis in terms of assessing fire fuel load. To calculate fire fuel, we first computed the narrowband greenness indices and selected
MRENDVI. Further, indices indicating level of canopy water content were evaluated and MSI was found most suitable. Lastly, the indices indicating dry vegetative material were evaluated and PSRI was found most suitable. Equal weightage was given to one representative from each category and values were stretched from 1 to 9 (ten classes), with 9 being the most heavily loaded with fuel.

\section{Results and discussion}

About 32 tree species were recorded across the sample sites in MWS. Table 2 gives the importance value index (IVI) for species calculated based on field-measured parameters. Dominant species in terms of IVI were A. latifolia followed by $T$. grandis, T. alata and S. roxburghii. The biodiversity map developed is mostly contributed by reflectance from woody tree species only.

\section{Dominant species mapping}

Spectral Angle Mapper (SAM) technique was used for species dominance mapping. It is a physically based spectral classification that uses an $n-D$ angle to match pixels to reference spectra. The algorithm determines spectral similarity between two spectra by calculating the angle between the spectra and treating them as vectors in a space with dimensionality equal to the number of bands ${ }^{46}$. Species IVI was calculated using field measurements and top six most important species were selected for dominance classification. Figure 5 shows reflectance curve for A. latifolia, T. alata, G. tiliifolia, S. cumini, S. roxburghii and $T$. grandis.

Image spectra collected for these species were used for dominance classification employing SAM technique. 
Table 4. Monthly rainfall at the MWS and SWS sites

\begin{tabular}{|c|c|c|c|c|c|c|c|c|c|c|}
\hline \multirow[b]{2}{*}{ Months } & \multicolumn{5}{|c|}{ SWS - Annual rainfall } & \multicolumn{5}{|c|}{ MRF - Annual rainfall } \\
\hline & 2012 & 2013 & 2014 & 2015 & 2016 & 2012 & 2013 & 2014 & 2015 & 2016 \\
\hline 3 & - & - & - & - & - & - & 46.44 & - & 57.16 & - \\
\hline 4 & - & - & - & - & - & 109.35 & 49.17 & 63.64 & 119.21 & 29.32 \\
\hline 5 & - & - & - & - & - & - & 113.05 & 240.85 & 150.66 & 128.94 \\
\hline 6 & 53.17 & 340.86 & - & 287.3 & 74.48 & 187.96 & 306.3 & 192.6 & 219.55 & 287.62 \\
\hline 7 & 341.38 & 637.91 & 369.09 & 321.07 & 378.97 & 177.5 & 417.26 & 438.53 & 248.38 & 366.12 \\
\hline 8 & 236.05 & 288.18 & 219.86 & 145.14 & 252.26 & 216.91 & 195.81 & 352.16 & 193.3 & 160.56 \\
\hline 9 & 395.07 & 352.64 & 217.49 & 247.51 & 241.04 & 95.73 & 144.1 & 168.51 & 146.45 & - \\
\hline 10 & - & 42.97 & - & - & 63.31 & 197.4 & 154.87 & 205.85 & 111.52 & - \\
\hline 11 & - & - & - & - & - & 47.77 & 70.3 & 73.03 & 164.88 & - \\
\hline 12 & & & & & & - & - & - & - & 69.66 \\
\hline Total & 1025.67 & 1662.56 & 806.44 & 1001.02 & 1010.06 & 1032.62 & 1497.3 & 1735.17 & 1411.11 & 1042.22 \\
\hline
\end{tabular}

Table 5. Distribution of VIIRS-detected fire on underlying fuel condition detected by AVIRIS-NG

\begin{tabular}{lc}
\hline Fuel load rank & Fire frequency $(\%)$ \\
\hline 1 & 20 \\
2 & 22 \\
3 & 16 \\
4 & 4 \\
5 & 8 \\
6 & 14 \\
7 & 6 \\
8 & 5 \\
9 & 6 \\
\hline
\end{tabular}

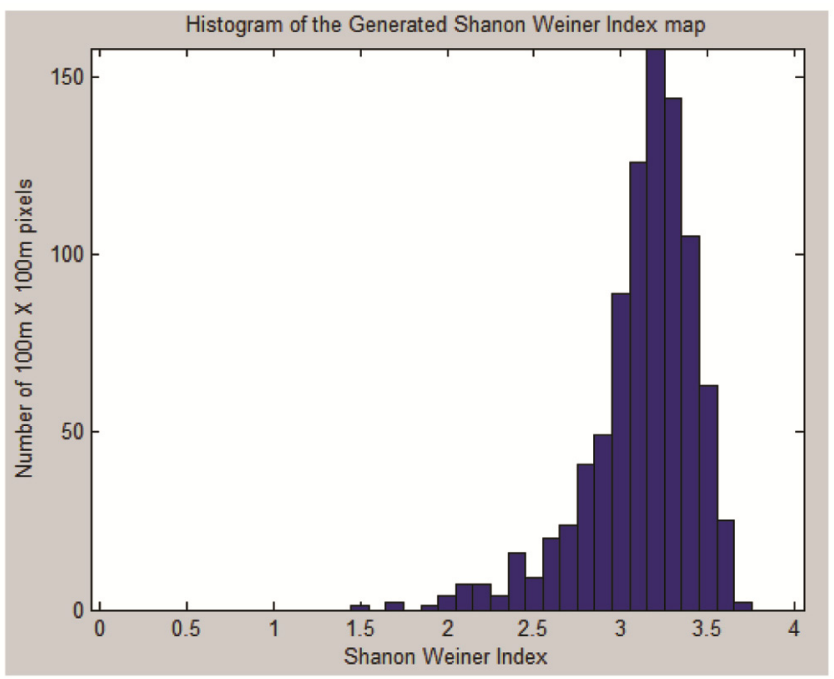

Figure 7. Histogram of the generated Shanon-Weiner index map of the region.

Figure 6 shows SAM classified species map. Table 3 gives the area covered under dominant species. SAM classification shows that nearly $40 \%$ area is dominated by A. latifolia and $27.5 \%$ by $T$. grandis. Ground-truth data from 15 plots were used for map validation. SAM tech- nique could classify the dominant species with $60 \%$ accuracy.

\section{Alpha diversity mapping}

From the histogram of Shannon-Weiner index map of the region (Figure 7), we conclude that it had $H^{\prime}$ ranging from 1.5 to 3.75 , with maximum number of pixels falling in 3.15-3.25 bins.

Comparison between the generated Shannon index map and the AVIRIS imagery (Figure 2), clearly shows that alpha diversity is more in regions which are relatively mesic, consistent with earlier findings for the region ${ }^{39}$. The converse is also noted (bottom right part of the map), i.e. exceptionally dry regions (with visibly dry soil) have much lower $H^{\prime}$ than their surroundings. Such studies help us in understanding the driving forces behind tree species diversity.

\section{Absorption peak decomposition technique}

AVIRIS image over Shimoga study site was filtered and then normalized continuum-removed spectrum for every pixel was generated. As per the 'endmember parameters' of each species, calculated from ASD spectrum analysis, a lookup table was generated. Each pixel was assigned a class according to the lookup table if the band parameters, particularly the peak centres matched. The weightage of that pixel was given as per the peak amplitude.

\section{Leaf phenology and rainfall}

At the two sites, viz. SWS and MWS, rainfall variability is significantly different. Rainfall dataset obtained from TRMM and PERSIANN (compared at site level) not only showed a difference in mean annual rainfall, but also variability in the number of months of rainfall (Table 4). 

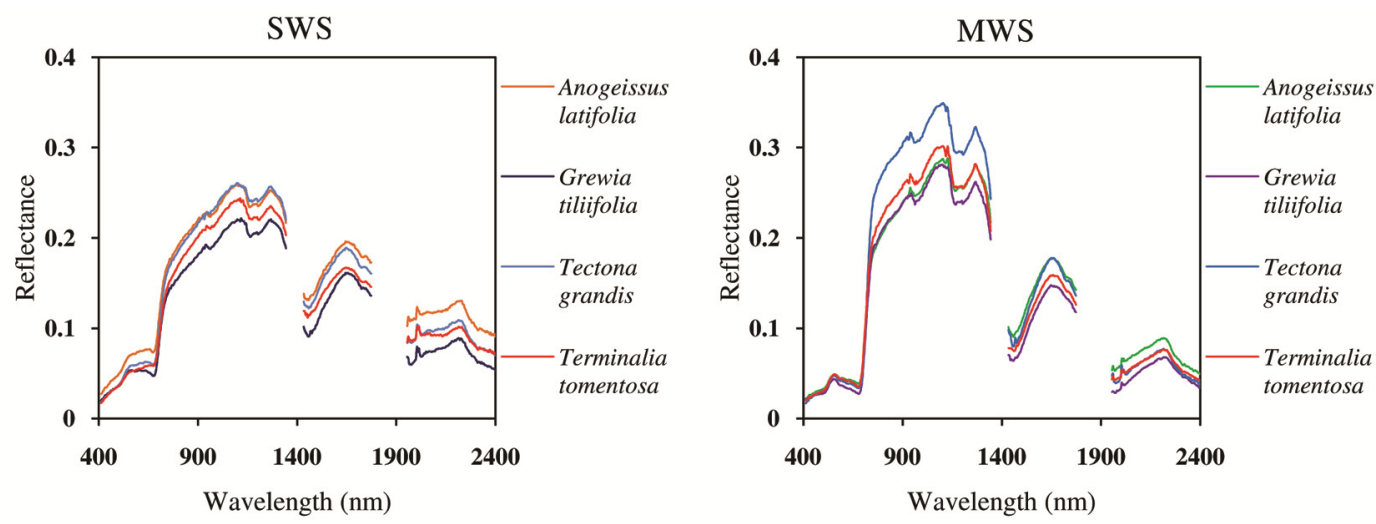

Figure 8. Comparison of reflectance curve for four species at the MWS and SWS study sites.
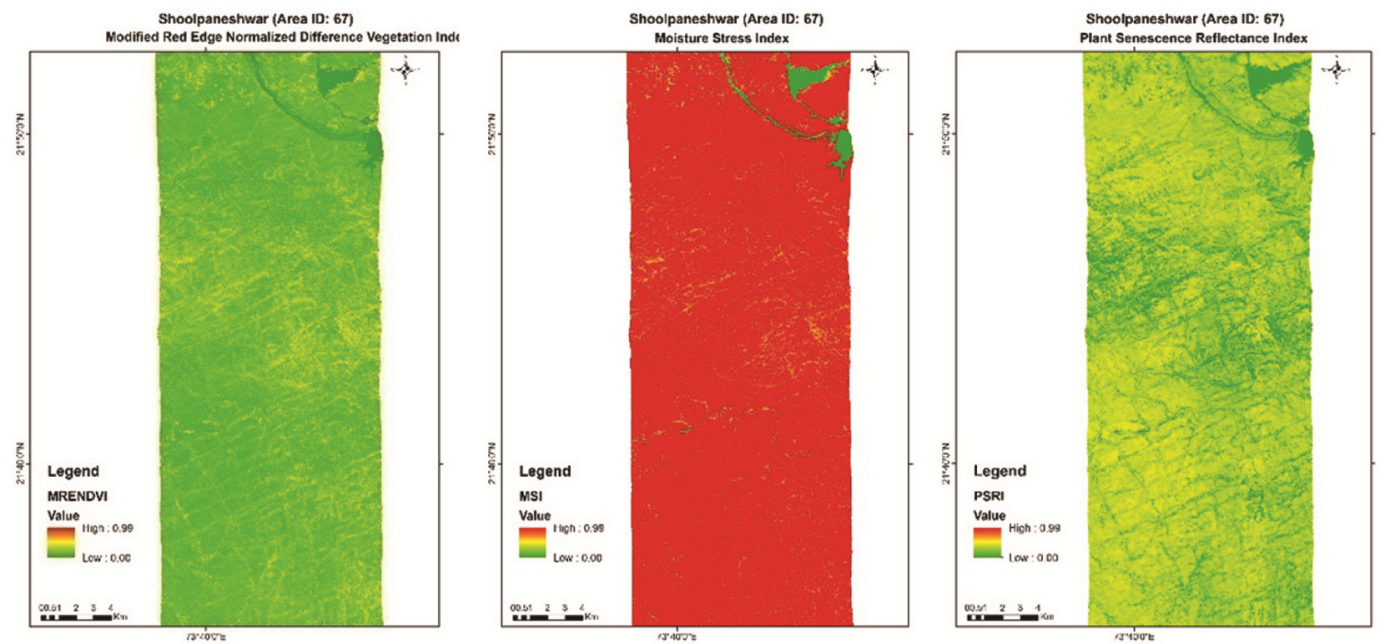

Figure 9. Vegetation indices (MRENDVI, MSI, PSRI) for fuel load estimation.

Field observations showed variability in tree species density and diversity distribution between the two sites, highlighting the impact of rainfall variability. Leaf phenology of common species at both the sites showed variability. This is evident in the spectra extracted from AVIRIS-NG dataset. Spectra of four tree species considered (A. latifolia, G. tiliifolia, T. grandis, T. tomentosa), showed distinctive patterns at both the study sites (Figure 8). At SWS, a dip in the chlorophyll absorptive region is much lesser than at MWS. It is different for all the four species at SWS, while it is similar for all of them at MWS.

Though there is a 15-day gap in the data acquisition of both the sites, vegetation indices of MRF reveal that higher rainfall ensures better Gross Primary Productivity (GPP) estimates for the growing trees. Observed phenology variability and differences in measured indices noted at canopy level of tropical tree species indicate their utility in providing better inputs to global land-surface phenology ${ }^{47}$. Accounting for different plant species, variability in their response to regional climate can be used to study the seasonality of ecosystem carbon exchange $^{48}$. Phenology impacted variability in spectra and measured vegetation indices seen in the same species across SWS and MRF highlight how the same species tinkers with its leaf phenology cycle in tropical regions.

\section{Fuel load estimation}

Figure 9 gives the output of individual indices and Figure 10 shows an overlay analysis-based forest fuel load map. MRENDVI, MSI and PSRI were estimated using the equations given earlier in the text.

The fuel load data could not be directly validated in the absence of field experiments designed for computing litter biomass and moisture content; however, actual fire counts from Suomi National Polar-Orbiting Partnership Visible Infrared Imaging Radiometer Suite (10 February 2016 to 7 June 2016) were checked (as proxy data) over different categories of fuel load ranging from 1 to 9 . It was interesting to note that only $38 \%$ of fire events fell in the category range 5-9 (Table 5), owing to anthropogenic 


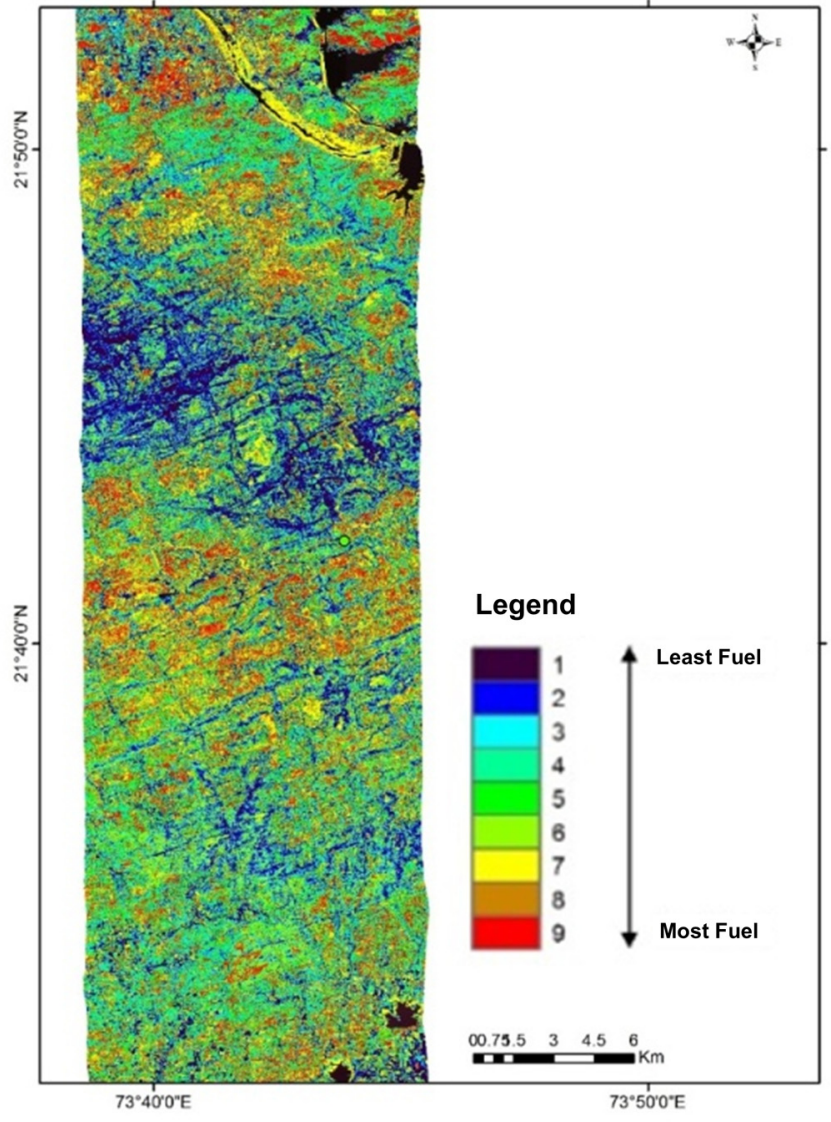

Figure 10. Forest fuel load map of SWS using AVIRIS-based vegetation indices.

factors involved in forest fires. Moreover, the dryness conditions would have changed over a period of time and newer scenarios would have developed at the later dates.

\section{Conclusion}

AVIRIS data with higher spectral and spatial resolution can be used in species mapping and $\alpha$-diversity mapping at community level. Accuracy achieved for the species classification is moderate $(60 \%)$ due to intermixing of species, since image-based spectra are used for species mapping. Field spectra collected using spectroradiometer for individual species will improve the classification accuracy. Precise geographic location of individual tree species for extracting image-based spectra will help in reducing the effect of intermixing of species in these spectra.

AVIRIS-NG data with higher spectral and spatial resolution provided a unique opportunity to carry out biochemical-level spectroscopy of the forest landscape in SWS. Overall stress and dryness condition of the deciduous forests could be detected, which allowed us to accurately estimate the plant-level greenness or senescence conditions and availability of material as fuel, which was not possible through available multispectral observations.

1. Reddy, C. S., Jha, C. S., Diwakar, P. G. and Dadhwal, V. K., Nationwide classification of forest types of India using remote sensing and GIS. Environ. Monit. Assess., 2015, 187, 777.

2. Reddy, C. S. et al., Quantification and monitoring of deforestation in India over eight decades (1930-2013). Biodivers. Conserv., 2016, 25, 93-116.

3. Hansen, M. C. et al., Humid tropical forest clearing from 2000 to 2005 quantified by using multitemporal and multiresolution remotely sensed data. Proc. Natl. Acad. Sci. USA, 2008, 105, 9439-9444.

4. Clark, M. L. and Roberts, D. A., Species-level differences in hyperspectral metrics among tropical rainforest trees as determined by a tree-based classifier. Remote Sensing, 2012, 4, $1820-1855$.

5. Asner, G. P., Hyperspectral remote sensing of canopy chemistry, physiology, and biodiversity in tropical rainforests. In Hyperspectral Remote Sensing Trop. Sub-Trop. For. (eds Kalacska, M. and Sanchez-Azofeifa, G. A.), CRC Press, 2008, pp. 261-296.

6. Clark, M. L., Identification of canopy species in tropical forests using hyperspectral data. In Hyperspectral Remote Sensing Veg. (eds Thenkabail, P. S. and Lyon, J. G.), CRC Press, 2016, p. 423.

7. Cla Barret, E. C. and Curtis, L. F., Introduction to Environmental Remote Sensing, Chapman \& Hall, London, 1992, 3rd edn.

8. Ustin, S. L. et al., Retrieval of foliar information about plant pigment systems from high resolution spectroscopy. Remote Sensing Environ., 2009, 113, S67-S77.

9. Asner, G. P., Biophysical and biochemical sources of variability in canopy reflectance. Remote Sensing Environ., 1998, 64, 234253.

10. Gao, B.-C. and Goetz, A. F. H., Column atmospheric water vapor and vegetation liquid water retrievals from airborne imaging spectrometer data. J. Geophys. Res. -Atmos., 1990, 95, 35493564.

11. Kokaly, R. F., Asner, G. P., Ollinger, S. V., Martin, M. E. and Wessman, C. A., Characterizing canopy biochemistry from imaging spectroscopy and its application to ecosystem studies. Remote Sensing Environ., 2009, 113, S78-S91.

12. Milton, N. M. and Mouat, D. A., Remote sensing of vegetation responses to natural and cultural environmental conditions. Photogramm. Eng. Remote Sensing, 1989, 55(8), 1167-1173.

13. Slaton, M. R., Hunt, E. R. and Smith, W. E., Estimating nearinfrared leaf reflectance from leaf structural characteristics. $\mathrm{Am}$. J. Bot., 2001, 88(2), 278-284.

14. Elvidge, C. D., Visible and near infrared reflectance characteristics of dry plant materials. Int. J. Remote Sensing, 1990, 11, 17751795.

15. Castro-Esau, K. L., Sánchez-Azofeifa, G. A., Rivard, B., Wright, S. J. and Quesada, M., Variability in leaf optical properties of Mesoamerican trees and the potential for species classification. Am. J. Bot., 2006, 93, 517-530.

16. Zhang, J., Rivard, B., Sánchez-Azofeifa, A. and Castro-Esau, K., Intra- and inter-class spectral variability of tropical tree species at La Selva, Costa Rica: implications for species identification using HYDICE imagery. Remote Sensing Environ., 2006, 105, $129-141$.

17. Carlson, K. M., Asner, G. P., Hughes, R. F., Ostertag, R. and Martin, R. E., Hyperspectral remote sensing of canopy biodiversity in Hawaiian lowland rainforests. Ecosystems, 2007, 10, 536-549.

18. Skoupý, O. et al., The use of hyperspectral remote sensing for mapping the age composition of forest stands. J. For. Sci., 2012, 58, 287-297. 
19. Christian, B. and Krishnayya, N. S. R., Classification of tropical trees growing in a sanctuary using hyperion (EO-1) and SAM algorithm. Curr. Sci., 2009, 96(12), 1601-1607.

20. Mitri, G. H. and Gitas, I. Z., Mapping postfire vegetation recovery using EO-1 Hyperion imagery. IEEE Trans. Geosci. Remote Sensing, 2010, 48, 1613-1618.

21. Vyas, D., Krishnayya, N. S. R., Manjunath, K. R., Ray, S. S. and Panigrahy, S., Evaluation of classifiers for processing hyperion (EO-1) data of tropical vegetation. Int. J. Appl. Earth Obs. Geoinf., 2011, 13, 228-235.

22. Wu, C., Wang, L., Niu, Z., Gao, S. and Wu, M., Nondestructive estimation of canopy chlorophyll content using hyperion and landsat/TM images. Int. J. Remote Sensing, 2010, 31, 2159-2167.

23. Thenkabail, P. S., Mariotto, I., Gumma, M. K., Middleton, E. M., Landis, D. R. and Huemmrich, K. F., Selection of hyperspectral narrowbands (HNBs) and composition of hyperspectral twoband vegetation indices (HVIs) for biophysical characterization and discrimination of crop types using field reflectance and Hyperion/EO-1 data. IEEE J. Sel. Top. Appl. Earth Obs. Remote Sensing, 2013, 6, 427-439.

24. Vyas, D., Christian, B. and Krishnayya, N. S. R., Canopy level estimations of chlorophyll and LAI for two tropical species (teak and bamboo) from hyperion (EO1) data. Int. J. Remote Sensing, 2013, 34, 1676-1690.

25. Cho, M. A., Sobhan, I., Skidmore, A. K. and De Leeuw, J., Discriminating species using hyperspectral indices at leaf and canopy scales. Int. Arch. Photogramm. Remote Sensing Spat. Inf. Sci., 2008, 37

26. Sánchez-Azofeifa, G. A., Castro, K. L., Rivard, B., Kalascka, M. R. and Harriss, R. C., Remote sensing research priorities in tropical dry forest environments. Biotropica, 2003, 35, 134-142.

27. Xiao, Q., Ustin, S. L. and McPherson, E. G., Using AVIRIS data and multiple-masking techniques to map urban forest tree species. Int. J. Remote Sensing, 2004, 25, 5637-5654.

28. Williams, A. P. and Hunt Jr, E. R., Using AVIRIS imagery to map invasive plants on rangelands: leafy spurge in northeastern Wyoming; https://aviris.jpl.nasa.gov/proceedings/workshops/02_docs/ 2002 Parker_Williams_web.pdf

29. Wessman, C. A., Aber, J. D., Peterson, D. L. and Melillo, J. M., Remote sensing of canopy chemistry and nitrogen cycling in temperate forest ecosystems. Nature, 1988, 335, 154.

30. Asner, G. P., Jones, M. O., Martin, R. E., Knapp, D. E. and Hughes, R. F., Remote sensing of native and invasive species in Hawaiian forests. Remote Sensing Environ., 2008, 112, 1912 1926.

31. Goodenough, D. G., Bhogal, A. S., Dyk, A. and Hudson, D., Data fusion of remote sensing data for forest parameter estimation. In Proceedings of the Fourth International Airborne Remote Sensing Conference and Exhibition/21 Canadian Symposium on Remote Sensing, ERIM International Inc, United States, 1999, p. 1816.

32. Gamon, J. A., Field, C. B., Roberts, D. A., Ustin, S. L. and Valentini, R., Functional patterns in an annual grassland during an AVIRIS overflight. Remote Sensing Environ., 1993, 44, 239-253.

33. Cleland, E. E., Chuine, I., Menzel, A., Mooney, H. A. and Schwartz, M. D., Shifting plant phenology in response to global change. Trends Ecol. Evol., 2007, 22, 357-365.

34. Morisette, J. T. et al., Tracking the rhythm of the seasons in the face of global change: phenological research in the 21 st century. Front. Ecol. Environ., 2009, 7, 253-260.

35. Wolkovich, E. M., Cook, B. I. and Davies, T. J., Progress towards an interdisciplinary science of plant phenology: building predictions across space, time and species diversity. New Phytol., 2014, 201, 1156-1162.

36. Féret, J.-B. and Asner, G. P., Tree species discrimination in tropical forests using airborne imaging spectroscopy. IEEE Trans. Geosci. Remote Sensing, 2013, 51, 73-84.

37. Clark, M. L., Roberts, D. A. and Clark, D. B., Hyperspectral discrimination of tropical rainforest tree species at leaf to crown scales. Remote Sensing Environ., 2005, 96, 375-398.

38. Castro-Esau, K. L., Sánchez-Azofeifa, G. A. and Caelli, T., Discrimination of lianas and trees with leaf-level hyperspectral data. Remote Sensing Environ., 2004, 90, 353-372.

39. Kalacska, M., Bohlman, S., Sanchez-Azofeifa, G. A., Castro-Esau, K. and Caelli, T., Hyperspectral discrimination of tropical dry forest lianas and trees: comparative data reduction approaches at the leaf and canopy levels. Remote Sensing Environ., 2007, 109, 406-415.

40. Arroyo-Mora, J. P., Kalacska, M., Chazdon, R., Civco, D., Obando-Vargas, G. and Sanchun, A., Assessing Recovery following Selective Logging of Lowland Tropical Forests based on Hyperspectral Imagery, Taylor and Francis Group-CRC Press, Boca Raton, FL, USA, 2008.

41. Féret, J.-B. and Asner, G. P., Mapping tropical forest canopy diversity using high-fidelity imaging spectroscopy. Ecol. Appl., 2014, 24, 1289-1296.

42. Champion, H. G. and Seth, S. K., A revised survey of the forest types of India. Govt Publication, New Delhi, 1968.

43. Joseph, S., Reddy, S. C., Pattanaik, C. and Sudhakar, S., Distribution of plant communities along climatic and topographic gradients in Mudumalia Wildlife Sanctuary (southern India). Biol. Lett., 2008, 45, 29-41.

44. Thompson, R. D., Gao, B.-C., Robert, O. G., Roberts, D. A., Dennison, P. E. and Sarah, R. L., Atmospheric correction for global mapping spectroscopy: ATREM advances for the HyspIRI preparatory campaign. Remote Sensing Environ., 2015; ISSN 00344257, http://dx.doi.org/10.1016/j.rse.2015.02.010.

45. Sims, D. A. and Gamon, J. A., Relationships between leaf pigment content and spectral reflectance across a wide range of species, leaf structures and developmental stages. Remote Sensing Environ., 2002, 81(2-3), 337-354.

46. Kruse, F. A. et al., The spectral image processing system (SIPS) interactive visualization and analysis of imaging spectrometer data. Remote Sensing Environ., 1993, 44, 145-163.

47. Shen, M., Tang, Y., Desai, A. R., Gough, C. and Chen, J., Can EVI-derived land-surface phenology be used as a surrogate for phenology of canopy photosynthesis? Int. J. Remote Sensing, 2014, 35, 1162-1174.

48. D'Odorico, P. et al., The match and mismatch between photosynthesis and land surface phenology of deciduous forests. Agric. For. Meteorol., 2015, 214, 25-38.

ACKNOWLEDGEMENTS. We thank the Director, National Remote Sensing Centre (NRSC), Hyderabad and Deputy Director, Remote Sensing Applications Area, NRSC, and the Director, Space Applications Centre, Ahmedabad for suggestions and encouragement. We also thank the AVIRIS team for providing AVIRIS data over Mudumalai Wildlife Sanctuary and Dr Bimal K. Bhattacharya, Head (AED) and PD, AVIRIS-NG for guidance.

doi: $10.18520 / \mathrm{cs} / \mathrm{v} 116 / \mathrm{i} 7 / 1124-1135$ 